\title{
Reallocation Costs and Efficiency ${ }^{\dagger}$
}

\author{
By Yuval Salant and Ron Sieged*
}

\begin{abstract}
We study the efficient allocation of a divisible asset when reallocation is costly. Two players initially divide an asset between them. At the time of this initial division the players'valuations for the asset are uncertain. After the uncertainty resolves, costly reallocation may take place. We first establish that the surplus associated with efficient reallocation monotonically increases or decreases in the concentration of the initial division for a wide range of cost specifications. We then characterize how the budget necessary to implement the efficient reallocation changes with the initial division. (JEL D11, D63, D81)
\end{abstract}

\section{A} ssets such as labor and capital are often allocated when there is uncertainty about their best use. And reallocating such assets after the uncertainty resolves- to increase the benefit they generate-is typically costly. With this cost in mind, how should an asset be allocated initially?

This question arises in the context of professional partnerships. For example, when partners in a law firm begin to handle the cases of a new client, they may face uncertainty about each partner's fit with the client's needs. And reallocating cases later on to the partner with the better fit is costly, because it requires that partner to learn what the other partners did with their cases. Anticipating this cost, how should the partners initially divide the cases?

A similar question arises in the context of inheritance planning. When parents draft a will to bequeath a family business or other assets to their children, they (and their children) may not know how much each child will value each asset at the time of the will's execution. Being concerned that any future reallocation of the assets may cause an emotional loss to the children whose shares in a particular asset decrease, how should the parents design their will?

\footnotetext{
* Salant: Kellogg School of Management, Northwestern University, 2001 Sheriden Road, Evanston, IL 60208 (e-mail: y-salant@northwestern.edu); Siegel: Department of Economics, The Pennsylvania State University, University Park, PA 16801 (e-mail: rus41@psu.edu). We thank Daron Acemoglu, David Besanko, Ed Lazear, Margaret Meyer, Benny Moldovanu, Alessandro Pavan, Larry Samuelson, Rakesh Vohra, Asher Wolinsky, and seminar participants at Bocconi, the Bounded Rationality Conference in Jerusalem, Cambridge University, Contests, Mechanisms, and Experiments Conference in Exeter, Hebrew University, Interdisciplinary Center (IDC), London School of Economics (LSE), University of Michigan, University of Minnesota, New York University Stern School of Business, Northwestern University, Ohio State University, Oxford University, Princeton University, Purdue University, Tel-Aviv University, University of Warwick, and University of Wisconsin for helpful comments and suggestions. We also thank a referee for helpful comments that substantially simplified some of the proofs. The second author thanks Tel-Aviv University and Hebrew University for their hospitality. The authors declare that they have no relevant or material financial interests that relate to the research described in this paper.

Go to http://dx.doi.org/10.1257/mic.20140262 to visit the article page for additional materials and author disclosure statement(s) or to comment in the online discussion forum.
} 
Another relevant setting is joint ventures. When two firms contract to build a plant that manufactures a widget used in the production of each firm's final product, they are often uncertain about their own demand for the plant's output. And any future redistribution of this output may involve costly adjustments to each firm's supply chain. How should the firms initially divide the portion of the output they may wish to reallocate later?

The reallocation costs in the joint venture setting may be thought of as convex in the amount reallocated, because firms may have the flexibility to first make the least costly adjustments to their supply chain. But in professional partnerships, learning some tasks previously assigned to a coworker may make it easier to learn an additional task, so reallocation costs may be concave. Similarly, in the spirit of Tversky and Kahneman's (1991) model of reference-dependent preferences, the marginal sensitivity to emotional losses decreases in the size of the loss, so reallocation costs in the context of inheritance planning may also be concave. Of course, in these and other settings, reallocation may also involve an overhead that is independent of the amount reallocated.

We establish that the curvature of the reallocation costs determines the optimal initial division of the asset. If reallocation costs consist of an overhead that is independent of the amount reallocated or are concave in the amount reallocated, it is optimal to choose as concentrated an initial division of the asset as possible. Thus, when reallocation involves a significant learning component, as may be the case when reassigning tasks in professional partnerships, a single partner should initially handle the workload associated with a particular client. Similarly, when reallocation involves emotional losses, as may be the case when reassigning ownership of family assets, the initial ownership of each asset should be concentrated in the hands of a single child (equity can be preserved by allocating additional monetary assets). In contrast, we establish that if reallocation costs are convex in the amount reallocated, as may be the case when reallocating output in a joint venture, it is optimal to choose as equal an initial division as possible.

We also establish that the curvature of the reallocation costs determines how large a budget players should set aside at the time of the initial division to facilitate optimal reallocation when their valuations are realized privately. If the curvature is sufficiently small, the required budget increases in the concentration of the initial division. The same is true even if the curvature is not small, provided that reallocation costs are small. And if reallocation costs are large, the budget also increases in the initial concentration for concave costs, but decreases in the initial concentration for convex costs.

We study a two-period model in which two symmetric risk-neutral players with quasi-linear utilities wish to allocate between them a divisible asset. The allocation consists of an initial division and a final allocation. The initial division is carried out in the first period, when players' valuations for the asset are still uncertain. ${ }^{1}$

\footnotetext{
${ }^{1}$ This fits settings in which postponing the initial division is too costly, as in the joint venture example in which valuations may be realized only after products are put on the market. When this is not the case, the tradeoff between early and delayed allocation can be determined by comparing the surplus in our model to the first-order statistic of players' valuations net of any delay costs, which is the value of delayed allocation.
} 
The final allocation takes place in the second period, after players' valuations are realized. When the final allocation differs from the initial division, the players incur reallocation costs. The reallocation costs may depend on players' valuations for the asset and on the amount reallocated.

Our first set of results characterizes how the initial division affects the maximal expected surplus, which is the expected sum of players' utilities generated by optimally reallocating the asset given the initial division. We establish that when reallocation costs are insensitive to the amount reallocated or concave in the amount reallocated, the maximal expected surplus is constant when the initial concentration, which is the larger share in the initial division, is smaller than some threshold, and then strictly increases in the initial concentration. In contrast, when reallocation costs are convex in the amount reallocated, the maximal expected surplus is still constant when the initial concentration is small enough, but then strictly decreases in the initial concentration. These results hold regardless of the magnitude of the reallocation costs, how valuations are distributed, and how valuations affect the costs. These parameters only influence the threshold above which the monotonicity becomes strict.

To obtain the maximal expected surplus for a given initial division, the appropriate final allocation must be implemented. The players can do this when their valuations are realized publicly by either contracting ex ante on the final allocation or by bargaining efficiently ex post. If valuations are realized privately, the maximal expected surplus can be obtained via a mechanism that induces players to report their valuations and implements the corresponding final allocation, provided that players' reallocation costs satisfy an increasing differences condition. But the expected payments specified by the mechanism may be positive, and thus generate a second-period deficit.

Our second set of results is about the effect of the initial concentration on the second-period deficit when reallocation costs depend on the amount reallocated but not on players' valuations. First, the second-period deficit is positive when the entire asset is initially owned by one player. This extends to the setting with reallocation costs Myerson and Satterthwaite's (1983) — henceforth, MS—result that in a buyer-seller setting efficient trade leads to a deficit. Second, when reallocation costs are sufficiently small (regardless of their curvature), or have a sufficiently small curvature (regardless of their magnitude), the second-period deficit increases in the initial concentration. This generalizes the results of Cramton, Gibbons, and Klemperer (1987) — henceforth, CGK — who study implementation of ex post efficiency without reallocation costs..$^{2}$ Finally, when reallocation costs are large in the sense that for every initial share there is a valuation that makes not reallocating optimal, the second-period deficit behaves like the maximal expected surplus: it increases in the initial concentration when reallocation costs are amount-insensitive or concave, and decreases in the initial concentration when reallocation costs are convex. Thus, in contrast to the results of CGK, with convex reallocation costs the deficit in the equal initial division is larger than when one player initially owns the entire asset.

\footnotetext{
${ }^{2}$ Other environments have been studied by Fieseler, Kittsteiner, and Moldovanu (2003); Jehiel and Pauzner (2006); and Segal and Whinston $(2011,2012)$.
} 
Another important difference between our setting and the literature on implementing ex post efficiency pioneered by MS and CGK is that what is ex post efficient in the setting with reallocation costs, and the associated maximal expected surplus, changes with the initial division. Understanding this dependency is an important part of our analysis. Moreover, players in our model initially interact when they do not own shares of the asset or have private information about their valuations. They can thus finance any second-period deficit via a first-period payment. When players' ability to make such inter-period payments is limited, our results about the second-period deficit identify the set of feasible initial concentrations, as well as the optimal initial concentrations in this set.

One factor we do not consider is investments to improve the asset that take place after it is initially allocated. When these investments are non-contractible, the allocation of the asset affects players' investment incentives and hence the surplus from the asset. How to optimally allocate assets in such settings is the focus of the property rights literature pioneered by Grossman and Hart (1986) and Hart and Moore (1990). There are important settings in which non-contractible investments are a dominant factor. There are other settings, such as inheritance planning, in which investments may play a smaller role, and joint ventures, in which investments may be contractible. There are also settings in which both investments and costly reallocation are present. In such settings, we expect both factors to jointly determine the optimal initial division.

There is also a finance literature that studies costly reallocation in the context of rebalancing a financial portfolio. Typical models in this literature study dynamic settings in which an investor can frequently rebalance his investments in a risk-free asset and a risky asset whose value is determined by a random process. The transaction costs involved in rebalancing may be proportional (linear), constant, or a fraction of the portfolio value. ${ }^{3}$ Our work differs from this literature in several respects. First, we study a strategic environment with more than one player. Second, because we are interested in understanding the effect of reallocation costs in general, rather than in a particular application, our specification of reallocation costs is richer than in this literature. Third, we study how different forms of reallocation costs influence the connection between the initial division of the asset and the surplus generated by optimally reallocating it, rather than taking the initial division as given (if it is at all relevant) and focusing only on optimal rebalancing.

\section{Environment}

Two risk-neutral players with quasi-linear utilities over money wish to allocate a divisible asset of size 1 between them. The allocation takes place in two periods, and consists of an initial division of the asset and its final allocation. The initial

\footnotetext{
${ }^{3}$ Cadenillas (2000) surveys infinite horizon, continuous time models of portfolio rebalancing in which a risky asset's value is determined by Brownian motion. There are also two-period models in which the portfolio can be rebalanced between the two periods. Mitchell and Braun (2004) consider this problem in the presence of convex transaction costs, and characterize for a risk-averse investor the efficient frontier that trades off risk and expected return. Dybvig (2005) considers a similar problem with linear or fixed costs when the investor has mean-variance preferences.
} 
division $\mathbf{S}=(s, 1-s)$ specifies player 1's initial share, $s \in[0,1]$, and player 2's initial share, $1-s$. We refer to $s_{\max }=\max \{s, 1-s\}$ as the initial concentration. The initial division takes place in the first period, when players' valuations for the asset are uncertain and are expected to be drawn from a symmetric joint probability distribution. The final allocation takes place in the second period, after players' valuations are realized. The final allocation specifies, for each realization $\left(v_{1}, v_{2}\right)$ of players' valuations, the final share $x\left(v_{1}, v_{2}\right)$ of player 1 (player 2's share is $\left.1-x\left(v_{1}, v_{2}\right)\right)$. There is no discounting between periods ${ }^{4}$

When the final allocation differs from the initial division, each player may incur reallocation costs. These costs may depend on the amount reallocated, whether a player's share increases or decreases, and players' valuations, but not on the player's identity. The cost of reallocating an amount $\Delta>0$ from the Losing player with valuation $v_{L}$ to the Gaining player with valuation $v_{G}$ is $C^{L}\left(v_{L}, v_{G}, \Delta\right) \geq 0$ to the losing player and $C^{G}\left(v_{L}, v_{G}, \Delta\right) \geq 0$ to the gaining player. The total cost $C\left(v_{L}, v_{G}, \Delta\right)=C^{L}\left(v_{L}, v_{G}, \Delta\right)+C^{G}\left(v_{L}, v_{G}, \Delta\right)$ is strictly positive.

The per-period utility of a player with valuation $v$ from a share $y$ of the asset is $y v$ (nonlinear utilities are discussed in Section V). Player 1's expected utility from the initial division is $E\left(s v_{1}\right)$, where the expectation is taken with respect to the distribution of players' valuations. Given a realization $\left(v_{1}, v_{2}\right)$ of players' valuations, player 1 's utility in the second period is

$$
\begin{aligned}
u_{1}\left(v_{1}, v_{2}, x, s\right)= & x\left(v_{1}, v_{2}\right) v_{1}-1_{x\left(v_{1}, v_{2}\right)<s} C^{L}\left(v_{1}, v_{2}, s-x\left(v_{1}, v_{2}\right)\right) \\
& -1_{x\left(v_{1}, v_{2}\right)>s} C^{G}\left(v_{2}, v_{1}, x\left(v_{1}, v_{2}\right)-s\right),
\end{aligned}
$$

where the first term is the player's benefit from the final allocation $x$, and the other two terms are the player's cost when he loses $s-x\left(v_{1}, v_{2}\right)$ or gains $x\left(v_{1}, v_{2}\right)-s$. Player 1's total expected utility from the initial division and final allocation is therefore $E\left(s v_{1}+u_{1}\left(v_{1}, v_{2}, x, s\right)\right)$. Player 2's expected utility is defined similarly.

Because players are ex ante symmetric, the sum of their expected utilities from the initial division, $E\left[s v_{1}+(1-s) v_{2}\right]$, does not depend on $s$. We thus ignore this expectation, and refer to the sum of players' utilities in the second period as the expected surplus:

$$
\begin{gathered}
E\left[x\left(v_{1}, v_{2}\right) v_{1}+\left(1-x\left(v_{1}, v_{2}\right)\right) v_{2}-1_{x\left(v_{1}, v_{2}\right)<s} C\left(v_{1}, v_{2}, s-x\left(v_{1}, v_{2}\right)\right)\right. \\
\left.-1_{x\left(v_{1}, v_{2}\right)>s} C\left(v_{2}, v_{1}, x\left(v_{1}, v_{2}\right)-s\right)\right] .
\end{gathered}
$$

Given a realization of players' valuations, we refer to the sum of players' utilities in the second period as the ex post surplus.

\footnotetext{
${ }^{4}$ This assumption does not affect any of our results.
} 


\section{A. Efficient Final Allocation}

Because players have quasi-linear utilities and can make monetary transfers, ex post Pareto efficiency is equivalent to maximizing the ex post surplus (given the initial division). We therefore consider an $\mathbf{S}$-efficient final allocation $x$, which maximizes the ex post surplus for any realization $\left(v_{1}, v_{2}\right)$, that is,

$$
\begin{aligned}
x^{\mathbf{s}}\left(v_{1}, v_{2}\right) \in \underset{x \in[0,1]}{\arg \max } & x v_{1}+(1-x) v_{2} \\
& -C\left(\min \left\{v_{1}, v_{2}\right\}, \max \left\{v_{1}, v_{2}\right\}, \max \{x-s, s-x\}\right) \cdot{ }^{5}
\end{aligned}
$$

We refer to the expected surplus of an S-efficient final allocation as the maximal expected surplus.

Example 1 illustrates an $\mathbf{S}$-efficient final allocation.

Example 1: Players' valuations are distributed independently and uniformly on $[0,1]$, and the total reallocation cost is $C<1$. For any initial division $\mathbf{S}$, an S-efficient final allocation has a "bang-bang" form. It allocates the entire asset to player 1 if the average benefit of doing so, $v_{1}-v_{2}$, is larger than the average cost, $C /(1-s)$ (region 1 in Figure 1), and to player 2 if $v_{2}-v_{1}$ is larger than $C / s$ (region 2 in Figure 1). Otherwise, it maintains the initial division (region 3 in Figure 1).

In the setting of Example 1, compare the specified $\mathbf{S}$-efficient final allocation to the final allocation that assigns the entire asset to the player with the higher valuation, which is efficient when there are no reallocation costs. First, the $\mathbf{S}$-efficient final allocation changes with the initial division. Second, it is not symmetric for $s \neq 1 / 2$. Third, the expected surplus changes with the initial division even when each player's initial share is positive. None of these hold for the final allocation that assigns the entire asset to the player with the higher valuation. ${ }^{6}$

\section{Initial Divisions and Maximal Expected Surplus}

This section studies how the maximal expected surplus changes with the initial division. We first consider reallocation costs that are insensitive to the amount reallocated, and then consider costs with either a concave or a convex variable component. Section III identifies conditions under which $\mathbf{S}$-efficient final allocations can be implemented.

\section{A. Amount-Insensitive Reallocation Costs}

Amount-insensitive costs do not depend on the amount reallocated, but may depend on players' valuations. One example is the legal and other fees associated with transferring ownership of a property, which may essentially be the same

\footnotetext{
${ }^{5}$ We require $C\left(v_{1}, v_{2}, \cdot\right)$ to be lower semi-continuous in its third argument so that a maximizer exists.

${ }^{6}$ In this final allocation, the expected surplus is $2 / 3-C$ if $S \notin\{(0,1),(1,0)\}$ and $2 / 3-C / 2$ otherwise.
} 


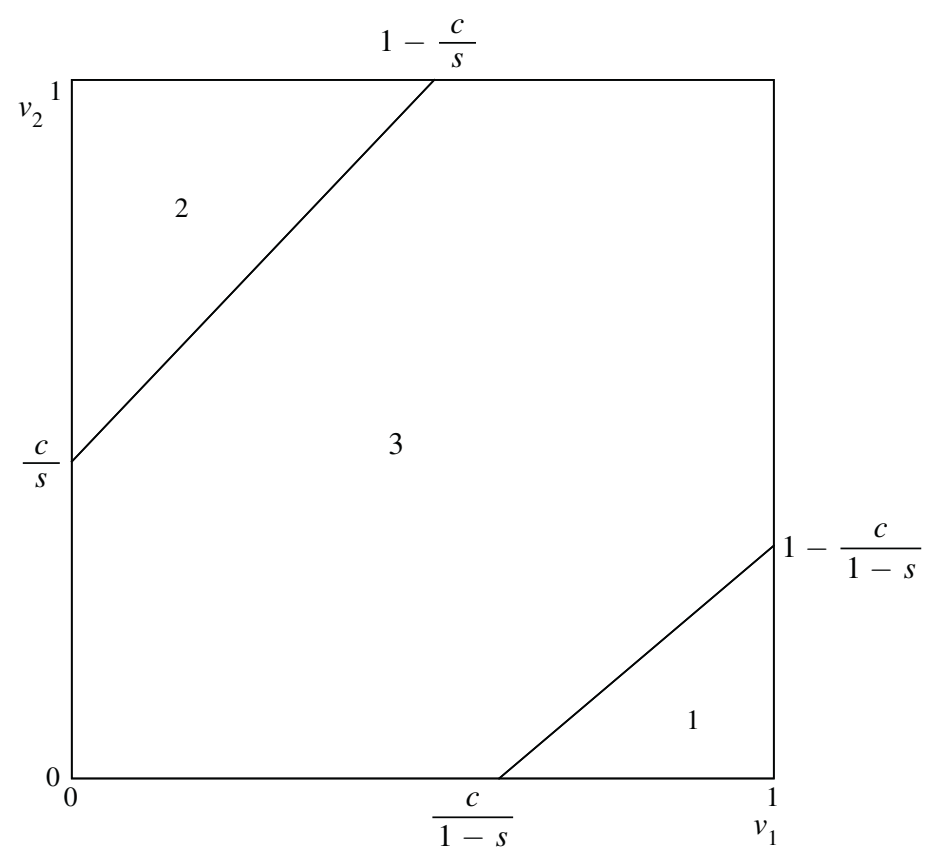

Figure 1. The S-efficient Final Allocation in Example 1 for $s>1 / 2$

regardless of how much of the property changes hands. The magnitude of this overhead may be affected by players' valuations when they correspond to the use to which the property is put (residential, commercial, etc.).

With amount-insensitive costs, an $\mathbf{S}$-efficient final allocation assigns the entire asset to the player with the higher valuation or maintains the initial division. This is because the benefit of reallocation increases in the amount reallocated, whereas the cost of reallocation does not. If this final allocation were independent of the initial division, the expected surplus would be maximized at an initial division that minimizes the expected reallocation costs. But the $\mathbf{S}$-efficient final allocation changes with the initial division, so the opposite may occur. For instance, in Example 1 with $C \geq 1 / 2$ the expected probability of reallocation increases in the initial concentration (region 1 in Figure 1 is then empty and region 2 increases in $s$ ), which implies that both the expected reallocation costs and the expected reallocation benefit increase in the initial concentration. The increase in the latter is larger than in the former, so the expected surplus is maximized when the expected reallocation costs are maximal.

The following result shows that regardless of how the expected reallocation costs change with the initial concentration, and regardless of the distribution of players' valuations, how the valuations affect reallocation costs, and the magnitude of the costs, the maximal expected surplus increases in the initial concentration. (The proofs of this and all other results are in the Appendix.)

PROPOSITION 1: The maximal expected surplus increases in the initial concentration. The increase is strict if and only if the initial concentration is larger than a threshold in $[1 / 2,1]$. 
The threshold depends on the distribution of players' valuations, how the valuations affect reallocation costs, and the magnitude of the costs. It is lower than 1 if and only if there is a positive measure of realizations for which the difference between players' valuations is strictly larger than the reallocation costs associated with the valuations.

To illustrate the proof of Proposition 1, consider the $\mathbf{S}$-efficient final allocation depicted in Figure 1, and take two valuations $v_{G}>v_{L}$. Because player 1 has the larger initial share and reallocation costs are constant, if it is optimal to reallocate the asset to player 1 when player 1 has the higher valuation, then it is optimal to reallocate the asset to player 2 when player 2 has the higher valuation. That is, region 1 is a subset of the reflection of region 2 along the diagonal. This implies that if we fix regions 1,2 , and 3, increase player 1's initial share slightly, and maintain the new initial division in region 3 (but reallocate as before in regions 1 and 2), the sum of the ex post surpluses of the two realizations $\left(v_{G}, v_{L}\right)$ and $\left(v_{L}, v_{G}\right)$ increases. This is because if $\left(v_{G}, v_{L}\right)$ is in region 1 , so $\left(v_{L}, v_{G}\right)$ is in region 2 , or $\left(v_{L}, v_{G}\right)$ is in region 3 , so $\left(v_{G}, v_{L}\right)$ is in region 3 , the increase in concentration has no effect on the sum; but if $\left(v_{G}, v_{L}\right)$ is in region 3 and $\left(v_{L}, v_{G}\right)$ is in region 2 , the sum increases because $v_{G}>v_{L}$. Optimizing the final allocation for the more concentrated initial division further increases the sum.

One implication of Proposition 1 relates to situations in which not every initial division is possible. This happens, for example, when learning one's valuation for the asset requires a minimal initial share, or when players have time or other constraints that restrict their initial share but are likely to be resolved before valuations are realized. This may also happen because of implementation-related issues, which we discuss in Section IV. In such cases, efficiency implies specifying as concentrated an initial division as possible.

When the initial division is not constrained, efficiency implies specifying a fully concentrated initial division and a final allocation that either maintains the initial division or reallocates the entire asset to the player with the higher valuation. Ex post one of the players has the entire asset, which is similar to the final allocation in the setting of CGK, in which reallocation is costless. But in contrast to that setting, the player who ends up with the asset may sometimes be the one with the lower valuation.

\section{B. Concave Reallocation Costs}

Reallocation costs may have a variable component that is concave in the amount reallocated. As mentioned in the introduction, this may be the case if reallocation requires learning by the gainer or results in an emotional loss for the loser. The total reallocation cost function is then concave, regardless of whether there are also amount-insensitive costs.

With concave reallocation costs, it is still optimal to reallocate the entire asset to the player with the higher valuation or to maintain the initial division, because the marginal reallocation cost decreases in the amount reallocated, whereas the marginal benefit is constant. The following result shows that similarly to the case of amount-insensitive costs, the maximal expected surplus increases in the initial concentration. 
PROPOSITION 2: The maximal expected surplus increases in the initial concentration. The increase is strict if and only if the initial concentration is larger than a threshold in $[1 / 2,1]$.

Propositions 1 and 2 extend to environments with more than two periods in which players' valuations in each period are drawn independently from their valuations in previous periods and the asset can be reallocated after each period's valuations are realized. Maximizing the (possibly discounted) sum of the expected surpluses across periods is done by initially allocating the entire asset to a single player, and in each period, based on players' realized valuations, either doing nothing or reallocating the entire asset to the other player. This maximizes the per-period surplus, because the entire asset is allocated to a single player at the beginning of every period, before the valuations for that period are realized. And the sum of expected surpluses cannot exceed what is obtained by maximizing the each period's expected surplus.

Proposition 2 may hint at how to assign ownership when players are loss averse. More concretely, suppose that a player views his initial share as a reference point, and experiences a mental loss when his final share is smaller than this reference point. 7 According to Tversky and Kahneman (1991), the marginal sensitivity to losses decreases in the amount lost, so reallocation costs are concave. Efficiency then implies allocating the asset initially to a single player, who will transfer ownership to the other player ex post if the other player's valuation is sufficiently higher than his. A relevant context may be inheritance planning: when parents wish to divide family assets among their children, they may be concerned that any future reallocation of the assets may result in mental losses to the children whose shares in a particular asset decrease. In this case, the parents should concentrate the ownership of each asset in the hands of one child, and can preserve equality by allocating additional monetary assets.

\section{Convex Reallocation Costs}

Unlike with mental losses, variable reallocation costs are often convex in the amount reallocated, for example, when players have the flexibility to reallocate the least costly units first. In this case, it is generally not optimal to reallocate the entire asset to one player or to maintain the initial division. Moreover, the qualitative relationship between the initial division and the maximal expected surplus depends on the magnitude of the amount-insensitive costs. We first consider convex variable costs without an amount-insensitive component, and then add this component. In the former case, we obtain the converse of Propositions 1 and 2, again with a threshold that depends on the distribution of players' valuations and how the valuations affect reallocation costs.

\footnotetext{
${ }^{7}$ This specification of a reference point differs from that of Kőszegi and Rabin (2006), which is the individual's expectation about his final asset ownership. As Tversky and Kahneman (1991, page 1046) note, "Although the reference state usually corresponds to the decision maker's current position, it can also be influenced by aspirations, expectations, norms, and social comparisons [...]." They also argue (page 1055) that the same mental loss does not arise with respect to corresponding monetary payments.
} 
PROPOSITION 3: With no amount-insensitive costs, the maximal expected surplus decreases in the initial concentration. The decrease is strict if and only if the initial concentration is larger than a threshold in $[1 / 2,1]$.

The threshold in Proposition 3 is $1 / 2$ if reallocation costs are sufficiently small and strictly convex. ${ }^{8}$ The equal initial division is then uniquely optimal. But when the threshold is higher than $1 / 2$ and lower than 1 , then unlike with amount-insensitive or concave costs, all the initial concentrations between $1 / 2$ and the threshold are optimal. A slight asymmetry between the players makes it optimal to assign an initial share higher than the threshold to the player with the higher expected valuation for the asset, as we discuss in Section V. In particular, when reallocation costs are so large that reallocation never takes place, which leads to a threshold of 1 , the asymmetry implies that it is uniquely optimal to initially allocate the entire asset to the player with the higher expected valuation.

While convex costs push toward an equal initial division, amount-insensitive costs push toward a concentrated initial division. When both costs are present and each player has only two possible valuations $v_{G}>v_{L}$, one of the costs dominates, so an optimal initial division is either a fully concentrated one or the equal one. To see which one is optimal, denote by $v_{\text {opt }}^{s}\left(v_{L}, v_{G}\right)$ the maximal surplus that can be generated by transferring up to $s$ shares from a player with valuation $v_{L}$ to a player with valuation $v_{G}$ when ignoring amount-insensitive costs, that is,

$$
v_{\text {opt }}^{s}\left(v_{L}, v_{G}\right)=\max _{y \leq s}\left\{y\left(v_{G}-v_{L}\right)-V C\left(v_{L}, v_{G}, y\right)\right\},
$$

where $V C$ denotes the variable convex costs. Let $\bar{C}=2 v_{\text {opt }}^{1 / 2}\left(v_{L}, v_{G}\right)-v_{\text {opt }}^{1}\left(v_{L}, v_{G}\right)$, which is nonnegative by convexity. We then obtain the following result.

PROPOSITION 4: If the amount-insensitive costs are lower than $\bar{C}$, then the expected surplus is maximized at the equal initial division. Otherwise, the expected surplus is maximized at the fully concentrated initial divisions.

Linear variable reallocation costs have $2 v_{o p t}^{1 / 2}=v_{o p t}^{1}$, so with amount-insensitive costs the optimal initial divisions are the fully concentrated ones.

Proposition 4 clearly applies when players have more than two possible valuations, provided that its conditions hold for a measure 1 of realizations. For example, the fully concentrated initial divisions are optimal if the amount-insensitive costs are always larger than $v_{o p t}^{1 / 2}$, because $v_{o p t}^{1} \geq v_{o p t}^{1 / 2}$. In general, however, it may be that neither the equal initial division nor the fully concentrated ones are optimal. Moreover, in contrast to Proposition 4, the optimal initial concentration need not increase in the magnitude of the amount-insensitive costs. The following example demonstrates this.

\footnotetext{
${ }^{8}$ This is because $A(s)$ in the proof of Proposition 3 is then strictly concave at $s=1 / 2$, since strict concavity holds for the integrands in the definition of $A(s)$ for a positive measure of players' valuations.
} 
Panel A. Sum of surpluses for $(0,2)$ and $(2,0)$

Panel B. Sum of surpluses for $(0,5 / 4)$ and $(5 / 4,0)$
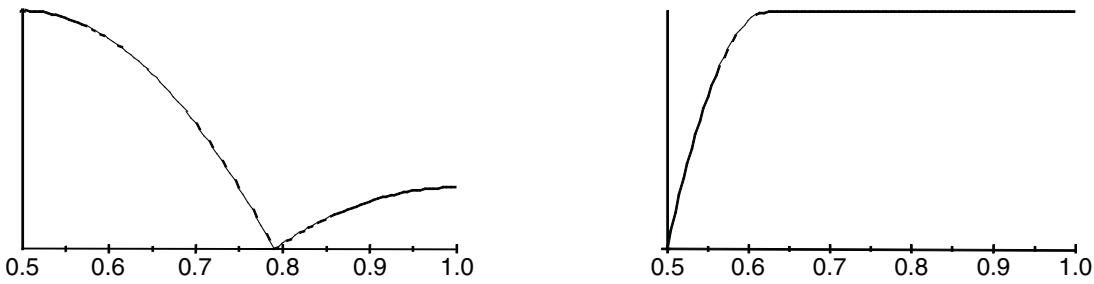

Panel C. Aggregate expected surplus

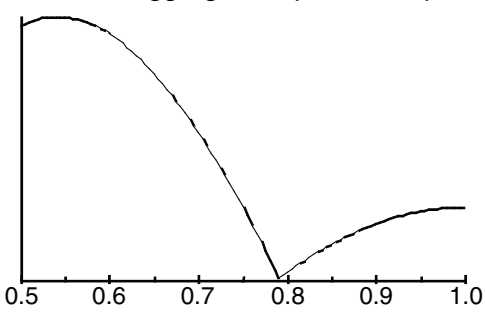

Figure 2. Expected Surpluses as a Function of the Initial Concentration in Example 2

Example 2: Players have three possible valuations, 0, 5/4, and 2, the distribution of players' valuations is uniform over the four realizations $(0,5 / 4),(5 / 4,0)$, $(0,2)$, and $(2,0)$, the variable cost is $\Delta^{2}$, and the amount-insensitive cost is $3 / 8$. Panel A of Figure 2 depicts how the sum of surpluses of the realizations $(0,2)$ and $(2,0)$ changes with the initial concentration. This sum is maximized at the equal initial division. Panel B of Figure 2 shows that the sum of surpluses of the realizations $(0,5 / 4)$ and $(5 / 4,0)$ is maximized at the fully concentrated initial divisions. The aggregate expected surplus, depicted in panel $\mathrm{C}$ of Figure 2, is maximized at the initial divisions with concentration $13 / 24$. The optimal initial concentration is not monotonic in the amount-insensitive cost, because for amount-insensitive costs of 0 and $25 / 64$ the optimal initial concentration is $1 / 2$.

\section{Implementing S-efficient Final Allocations}

When players' valuations are realized publicly, the players can contract ex ante on an initial division $\mathbf{S}$ and an $\mathbf{S}$-efficient final allocation, and divide the resulting surplus between them via side payments (monetary transfers). An S-efficient final allocation is also implementable without contracting, as long as players can bargain efficiently ex post and use a first-period side payment to compensate the player whose expected ex post bargaining position is weaker.

It is also possible to implement $\mathbf{S}$-efficient final allocations when players' valuations are realized privately. To induce players to report their valuations truthfully, second-period payments that depend on players' reports must be incorporated. Such payments exist when players' valuations are correlated, and also when the valuations are independent and players have "private values," i.e., $C^{L}$ does not depend on 
$v_{G}$ and $C^{G}$ does not depend on $v_{L} \cdot 9$ Such payments also exist when players do not have private values, as the following observation shows.

OBSERVATION 1: An S-efficient final allocation is implementable as an ex post equilibrium if both players' marginal reallocation costs increase in the losing player's valuation and decrease in the gaining player's valuation. ${ }^{10}$

With independent valuations the sum of the second-period payments to the players may be strictly positive, creating a second-period "deficit." This deficit will be financed by the players in the first period, when they initially interact to decide on the initial division and have no private information. ${ }^{11}$ The ability to make a first-period payment in order to finance the second-period deficit is not present in MS and CGK, who considered a setting with costless reallocation, in which players own shares of the asset and have privately-known valuations at the outset (henceforth: the standard setting). We now proceed to investigate how the second-period deficit in our model changes with the initial concentration, and compare this to how the deficit in the standard setting changes with the initial concentration.

\section{Reallocation Costs and Second-Period Deficit}

To facilitate the comparison and simplify the analysis, we focus on Bayesian Nash implementation and assume that players' valuations are independent, reallocation costs depend only on the amount reallocated, and each player can walk away with his initial share after he privately learns his valuation. ${ }^{12}$ Each valuation is drawn from the interval $[0,1]$ according to a CDF $F$, which has a strictly positive density $f$.

In the standard setting, increasing the initial concentration does not affect the efficient ex post allocation rule or the expected surplus. The change in players' outside option, however, increases the payment to the player with the larger initial share, and decreases the payment to the player with the smaller initial share. CGK showed that the increase is larger than the decrease, so the deficit, which is the sum of the payments, increases in the initial concentration. Thus, for any bound on the allowed deficit, the set of initial concentrations with a smaller deficit is an interval with lower bound $1 / 2$. All these feasible initial concentrations are optimal, because each of them maximizes the expected surplus. In addition, the deficit is negative at the equal initial division and positive when the initial concentration is sufficiently high.

We now consider how the second-period deficit in the setting with reallocation costs changes with the initial concentration. Section IVA shows that when

\footnotetext{
${ }^{9}$ For correlated valuations see Crémer and McLean (1988), McAfee and Reny (1992), and Kosenok and Severinov (2008). For private values one can use a Vickrey-Clarke-Groves (VCG) mechanism (see Mas-Colell, Whinston, and Green 1995, Chapter 23).

${ }^{10}$ In an ex post equilibrium, given that the other player reports truthfully, a player prefers to report his valuation truthfully for any valuation of the other player.

${ }^{11}$ The budget can be balanced ex post by modifying the second-period payments as in Arrow (1979) and d'Aspremont and Gérard-Varet (1979).

${ }^{12}$ Most of the results generalize to private values with cost functions $C^{L}$ and $C^{G}$ that are differentiable with respect to $v_{L}$ and $v_{G}$ and whose derivatives are uniformly bounded across all valuations and allocations.
} 
reallocation costs are small (independently of their curvature) or when their curvature is small (independently of their magnitude), the deficit behaves similarly to the deficit in the standard setting. Section IVB shows that when reallocation costs are large, the second-period deficit behaves like the maximal expected surplus, characterized in Section II.

\section{A. Small or Almost-Linear Reallocation Costs}

Consider first small reallocation costs. For any initial concentration $s$ sufficiently close to $1 / 2$, there is an $\varepsilon>0$ such that if reallocation costs are bounded above by $\varepsilon$, then the second-period deficit is negative on $[1 / 2, s]$ and increases in the initial concentration on $[s, 1]$. This is because the second-period deficit is continuous in the reallocation costs, and the derivative of the deficit in the standard setting is bounded away from 0 on $[s, 1]$. Thus, for sufficiently small reallocation costs the set of initial concentrations with a negative second-period deficit is an interval with lower bound $1 / 2$, just like in the standard setting. Note, however, that the optimal initial concentration is unique, rather than the entire interval, provided that reallocation costs are nowhere linear. This is because for sufficiently small costs the thresholds in Section II for strict monotonicity of the maximal expected surplus are equal to $1 / 2$. Thus, the optimal initial concentration is $1 / 2$ with convex costs, and the upper bound of the interval with amount-insensitive or concave costs. Consequently, as reallocation costs vanish, the optimal initial concentration remains $1 / 2$ with convex costs and converges to the upper bound of the interval of the standard setting with amount-insensitive or concave costs.

Consider next reallocation costs with a small curvature, i.e., close to linear. By continuity, the second-period deficit behaves similarly to the case of linear reallocation costs, which is characterized by the following result.

PROPOSITION 5: With linear reallocation costs the second-period deficit increases in the initial concentration. The increase is strict if and only if the slope of the costs is smaller than $1 / 2$.

Propositions 2 and 3 imply that the maximal expected surplus is constant in the initial concentration when reallocation costs are linear. Therefore, given any bound on the second-period deficit, any initial concentration with a smaller second-period deficit is optimal, and if the set of these initial concentrations is not empty, then it is an interval with lower bound $1 / 2$. This extends CGK's characterization of the set of optimal initial divisions to the setting with linear reallocation costs.

We now turn to substantial reallocation costs, whose magnitude and curvature may not be small.

\section{B. Substantial Reallocation Costs}

Reallocation costs are substantial if for every initial share, there is a valuation for which no reallocation takes place when the player with the initial share has this valuation. 
Reallocation costs with an amount-insensitive component of at least 1/4 are substantial, since for every initial share $s$ no reallocation takes place for the valuation $v=s$. This is because the maximal reallocation gain $s(1-s)$ (generated by reallocating the share $s$ to a player with valuation 1 or reallocating the share $1-s$ from a player with valuation 0 ) is no higher than $1 / 4$ for every $s$. Concave reallocation costs for which the cost of reallocating the entire asset is at least $1 / 2$ are also substantial, because by concavity the cost of reallocating a share $s$ of the asset is no less than $s / 2$, so no reallocation takes place for the valuation $1 / 2$. For the same reason, convex reallocation costs in which the marginal reallocation cost is at least $1 / 2$ are also substantial.

Given an initial division, if reallocation costs are substantial, each player has a valuation such that the initial division is maintained for any valuation of the other player. This valuation corresponds to an "opt-out type" à la Segal and Whinston (2012), who study a setting with costless reallocation, in which the efficient decision rule is independent of players' initial shares. Segal and Whinston (2012) show that the MS formula for the deficit extends to their setting, provided that each player has an opt-out type. That is, the deficit is equal to the "gains from trade," which is the difference in expected surplus between the efficient decision rule and the initial property rights. ${ }^{13}$ The same formula also applies in our setting for a fixed initial division. We therefore obtain the following result.

PROPOSITION 6: When reallocation costs are substantial, the second-period deficit is equal to the maximal expected surplus minus a player's expected valuation for the asset.

Proposition 6 has several implications. The first implication is that Section II fully characterizes how the second-period deficit changes with the initial division: it increases in the initial concentration if reallocation costs are amount-insensitive or concave, and decreases in the initial concentration if reallocation costs are convex.

The second implication is that the second-period deficit is strictly positive if reallocation takes place with positive probability, because the maximal expected surplus then exceeds a players' expected valuation for the asset.

The third implication is that for any bound on the second-period deficit, if the set of initial concentrations with a smaller second-period deficit is not empty, then it is an interval with lower bound $1 / 2$ if reallocation costs are amount-insensitive or concave, similarly to the standard setting, and it is an interval with upper bound 1 if reallocation costs are convex, in contrast to the standard setting. Thus, for convex costs it may be possible to implement ex post efficiency when one player initially owns the entire asset but not when the asset is divided equally. Another difference is that in the standard setting every initial concentration in the interval of feasible initial concentrations is optimal, whereas in the setting with reallocation costs this is not the case when the threshold for strict monotonicity of the maximal expected surplus is smaller than the upper bound of the interval.

\footnotetext{
${ }^{13}$ See Segal and Whinston's (2012) equation (15) for $N=2$.
} 
The fourth implication is that a pointwise increase in reallocation costs decreases the second-period deficit, because it implies a decrease in the maximal expected surplus. As a result, for any bound on the second-period deficit, increasing reallocation costs pointwise increases the set of initial concentrations with a smaller deficit. When reallocation costs are high enough so that no reallocation takes place, there is no second-period deficit, so this set becomes the interval $[1 / 2,1]$.

Finally, the MS impossibility result continues to hold in the setting with reallocation costs even if they are not substantial, as long as some trade is optimal. This is because at a fully concentrated initial division the MS formula for the deficit continues to hold, since each player has a valuation for which no reallocation takes place. 14

\section{Concluding Remarks}

This paper studied how to initially divide an asset when reallocation is costly. The main takeaway is that reallocation costs effect the optimal initial division of the asset and the budget required to optimally reallocate the asset in a systematic way. We conclude with a discussion of how modifying our symmetry, linear-valuations, and two-player assumptions effects the optimal initial division.

Asymmetric Players: The symmetry assumption allowed us to isolate the effect of reallocation costs on the optimal initial division. When players are asymmetric, the asymmetry interacts with reallocation costs to determine the optimal initial division.

One possible asymmetry is in the distribution of players' valuations. When reallocation costs are amount insensitive or concave, the optimal initial division still assigns the entire asset to one of the players. ${ }^{15}$ If, for example, for any pair of possible valuations $v_{G}>v_{L}$ player 1 is more likely to have the higher valuation, that is, $f\left(v_{G}, v_{L}\right)>f\left(v_{L}, v_{G}\right)$, where $f$ is the density of the distribution of valuations, then the optimal initial division assigns the entire asset to player 1 . Note, however that if the asset could initially either be assigned to player 2 or divided between the players with a slightly larger share for player 1 , the former option might be better, despite player 1's advantage. When reallocation costs are convex, under the aforementioned assumption on $f$, player 1's initial share is optimally larger than player 2's share. This is true independently of the first-period expected surplus, which also pushes toward a higher initial share for player 1 .

Nonlinear Valuations: When players' utilities from the asset are not linear in their share, the initial division effects the first-period expected surplus as well as the second-period expected surplus. The effect on the first-period expected surplus is straightforward: If each player's utility from the asset is concave (convex) in his share, then the first-period expected surplus decreases (increases) in the initial

\footnotetext{
${ }^{14}$ This is the lowest type for the "buyer" and the highest type for the "seller" in the terminology of MS.

${ }^{15}$ This is because the proof of Propositions 1 and 2 shows that the maximal expected surplus is convex in player 1's initial share for any distribution of players' valuations.
} 
concentration. The effect on the second-period expected surplus is less straightforward. For example, if utilities are sufficiently convex in share and reallocation costs are concave in the amount reallocated, then the entire asset may sometimes be optimally reallocated to the player with the lower valuation. Nevertheless, the maximal expected surplus increases in the initial concentration when the utility from the asset is convex in the share and reallocation costs are amount-insensitive or concave in the amount reallocated, and decreases in the initial concentration when the utility from the asset is concave in the share and reallocation costs are convex in the amount reallocated, regardless of how valuations affect the reallocation costs. ${ }^{16}$

More than Two Players: Extending our analysis to $N>2$ players requires a more general notion of concentration. Given two initial divisions $\mathbf{S}=\left(s_{1}, \ldots, s_{N}\right)$ and $\mathbf{T}=\left(t_{1}, \ldots, t_{N}\right)$, we say then $\mathbf{S}$ is more concentrated than $\mathbf{T}$ if $\mathbf{S}$ majorizes $\mathbf{T}$, that is, if when the shares in $\mathbf{S}$ and in $\mathbf{T}$ are arranged in decreasing order, we have that $\sum_{i=1}^{k} s_{i} \geq \sum_{i=1}^{k} t_{i}$ for every $k=1, \ldots, N$. In settings with two players, majorization induces a complete ordering on the set of initial divisions. With three or more players, the induced ordering is a partial one. Assuming that reallocation costs are additive across reallocations, and the costs of each reallocation depend only on the amount reallocated and on the valuations of the gaining player and the losing player, we obtain the following generalization of our results.

\section{PROPOSITION 7: Suppose that $\mathbf{S}$ is more concentrated than $\mathbf{T}$. Then,}

(i) If reallocation costs are amount insensitive or concave in the amount reallocated, then the maximal expected surplus associated with $\mathbf{S}$ is higher than that associated with $\mathbf{T}$.

(ii) If reallocation costs are convex in the amount reallocated, then the maximal expected surplus associated with $\mathbf{T}$ is higher than that associated with $\mathbf{S}$.

In particular, because the initial divisions that assign the entire asset to a single player majorize every other initial division, they are optimal when reallocation costs are amount insensitive or concave. And because the equal initial division is majorized by every other initial division, this division is optimal when reallocation costs are convex.

\section{APPENDIX}

\section{PROOF OF PROPOSITIONS 1 AND 2:}

It suffices to prove Proposition 2, because Proposition 1 is a special case. An S-efficient final allocation assigns the entire asset to the player with the strictly

\footnotetext{
${ }^{16}$ When the utility is convex in $x$, a proof similar to those of Propositions 1 and 2 applies, because an $S$-efficient final allocation still assigns the entire asset to one player or maintains the initial division. The comment at the end of the proof of Proposition 3 explains how to modify the proof to accommodate a utility that is concave in $x$.
} 
higher valuation if the other player's initial share is sufficiently large, and otherwise maintains the initial division. Thus, the maximal expected surplus is

$$
A(s)=E\left(\max \left\{v_{1}-C\left(v_{2}, v_{1}, 1-s\right), v_{2}-C\left(v_{1}, v_{2}, s\right), s v_{1}+(1-s) v_{2}\right\}\right)
$$

Because each of the three functions over which the maximum is taken is convex in $s \in[0,1]$, the maximum of convex functions is a convex function, and the integral of convex functions is a convex function, we have that $A$ is a convex function of $s \in[0,1]$. In addition, $A$ is symmetric around $1 / 2$ because $F$ is symmetric. Convexity and symmetry imply that $A$ weakly decreases on $[0,1 / 2]$ and weakly increases on $[1 / 2,1]$. This also implies that $A$ is constant on $\left[1 / 2, s_{\text {const }}\right]$, where $s_{\text {const }}=\max _{s^{\prime} \geq 1 / 2}\left\{A\left(s^{\prime}\right)=A(1 / 2)\right\}$, and strictly increases on $\left[s_{\text {const }}, 1\right]$.

\section{PROOF OF PROPOSITION 3:}

Ignoring realizations for which both players have the same valuation, so the asset is not reallocated, the maximal expected surplus is

$$
\begin{aligned}
A(s)= & \int_{v_{1}>v_{2}} \max _{x \in[s, 1]}\left(x v_{1}+(1-x) v_{2}-C\left(v_{2}, v_{1}, x-s\right)\right) d F \\
& +\int_{v_{2}>v_{1}} \max _{x \in[0, s]}\left(x v_{1}+(1-x) v_{2}-C\left(v_{1}, v_{2}, s-x\right)\right) d F
\end{aligned}
$$

Because $F$ is symmetric, $A(s)$ is symmetric around $1 / 2$. Thus, as in the proof of Propositions 1 and 2 , it suffices to show that $A(s)$ is concave in $s \in[0,1]$. We show that the first integral is concave; showing that the second one is concave is analogous.

Fix $v_{1}>v_{2}$, and for each $s \in[0,1]$ suppose that $h(s)$ $=\max _{x \in[s, 1]}\left(x v_{1}+(1-x) v_{2}-C\left(v_{2}, v_{1},-s\right)\right)$ is attained at $x(s)$. Because the integral of concave functions is concave, it suffices to show that $h(s)$ is concave. Consider shares $s$ and $s^{\prime}$ and $\alpha \in[0,1]$, and let $t=\alpha s+(1-\alpha) s^{\prime}$. Then $y=\alpha x(s)+(1-\alpha) x\left(s^{\prime}\right) \in[t, 1]$. We have that

$$
\begin{aligned}
h(t) \geq & y v_{1}+(1-y) v_{2}-C\left(v_{2}, v_{1}, y-t\right) \\
= & \alpha\left(x(s) v_{1}+(1-x(s)) v_{2}\right) \\
& +(1-\alpha)\left(x\left(s^{\prime}\right) v_{1}+\left(1-x\left(s^{\prime}\right)\right) v_{2}\right)-C\left(v_{2}, v_{1}, y-t\right) \\
= & \alpha h(s)+(1-\alpha) h\left(s^{\prime}\right)+\alpha C\left(v_{2}, v_{1}, x(s)-s\right)+(1-\alpha) C\left(v_{2}, v_{1}, x\left(s^{\prime}\right)-s^{\prime}\right) \\
& -C\left(v_{2}, v_{1}, \alpha(x(s)-s)+(1-\alpha)\left(x\left(s^{\prime}\right)-s\right)\right) \\
\geq & \alpha h(s)+(1-\alpha) h\left(s^{\prime}\right)
\end{aligned}
$$

which concludes the proof. 
Comment: If player $i$ 's utility from a share $x$ of the asset is $V\left(v_{i}, x\right)$, which is concave in $x$, the proof requires a modification. This is because when a player's initial share is large it may be optimal to reallocate some of the asset to the other player even if he has the lower valuation (since he may have the higher marginal valuation). To accommodate this, modify $h(s)$ so that the maximum is taken over $x \in[0,1]$. Because $V$ is concave, inequalities similar to the ones above show that $h(s)$ is concave when $x(s)<s$ and $x\left(s^{\prime}\right)<s^{\prime}$ or $x(s)>s$ and $x\left(s^{\prime}\right)>s^{\prime}$. Suppose that $x(s)<s$ and $x\left(s^{\prime}\right)>s^{\prime}$. Then, if $y<t$, convexity implies that

$$
\begin{aligned}
C\left(v_{1}, v_{2}, t-y\right) & \leq \alpha C\left(v_{1}, v_{2}, s-x(s)\right) \\
& \leq \alpha C\left(v_{1}, v_{2}, s-x(s)\right)+(1-\alpha) C\left(v_{2}, v_{1}, x\left(s^{\prime}\right)-s^{\prime}\right),
\end{aligned}
$$

and similarly if $y>t$. Similarly, if $x(s)>s$ and $x\left(s^{\prime}\right)<s^{\prime}$. Thus, $h(s)$ is concave.

\section{PROOF OF PROPOSITION 4:}

If both players have the same valuation, the asset is not reallocated. We therefore consider the maximal expected surplus $A(s)$ associated with the two realizations $\left(v_{L}, v_{G}\right)$ and $\left(v_{G}, v_{L}\right)$. We first show that $A(s)$ is maximized in either a fully concentrated initial division or the equal one. Denote by $s_{0}\left(v_{L}, v_{G}\right)$ the minimal unconstrained share for which reallocation is beneficial, that is,

$$
s_{0}\left(v_{L}, v_{G}\right)=\inf \left\{s: s\left(v_{G}-v_{L}\right)-V C\left(v_{L}, v_{G}, s\right) \geq \operatorname{AIC}\left(v_{L}, v_{G}\right)\right\},
$$

where $\operatorname{AIC}\left(v_{L}, v_{G}\right)$ are the amount-insensitive costs, and $s_{0}\left(v_{L}, v_{G}\right)=1$ if this set is empty. If the smaller initial share in an initial division is larger than $s_{0}\left(v_{L}, v_{G}\right)$, then reallocating some of the asset to the player with the higher valuation is beneficial independently of his initial share, and the amount reallocated is determined by the convex variable component $V C$. The proof of Proposition 3 therefore shows that $A(s)$ restricted to $\left[s_{0}\left(v_{L}, v_{G}\right), 1-s_{0}\left(v_{L}, v_{G}\right)\right]$ is maximized at $s=1 / 2$. It therefore suffices to show that $A(s)$ restricted to $\left[0, s_{0}\left(v_{L}, v_{G}\right)\right] \cup\left[1-s_{0}\left(v_{L}, v_{G}\right), 1\right]$ is maximized at $s=0,1$. But for an initial division with $s$ in this range, $A(s)$ is equal to $v_{L}+v_{G}$ plus any additional benefit generated by reallocating shares to the player with the higher valuation when he has the smaller initial share. This additional benefit increases in the concentration because more of the asset can be transferred to this player.

To determine which initial division is optimal, suppose that $\operatorname{AIC}\left(v_{L}, v_{G}\right)>\bar{C}$. If $s_{0}\left(v_{L}, v_{G}\right)>1 / 2$, then the proof above shows that $A(1) \geq A(1 / 2)$. If $s_{0}\left(v_{L}, v_{G}\right) \leq 1 / 2$, then the $A(1 / 2)=v_{L}+v_{G}+2 v_{\text {opt }}^{1 / 2}\left(v_{L}, v_{G}\right)-$ $2 A I C\left(v_{L}, v_{G}\right)$, and $A(1)=v_{L}+v_{G}+v_{o p t}^{1}\left(v_{L}, v_{G}\right)-A I C\left(v_{L}, v_{G}\right)$, which is larger by assumption.

Now suppose that $\operatorname{AIC}\left(v_{L}, v_{G}\right) \leq \bar{C}$. This implies that $s_{0}\left(v_{L}, v_{G}\right) \leq 1 / 2$. Otherwise, $v_{\text {opt }}^{1 / 2}\left(v_{L}, v_{G}\right)<\operatorname{AIC}\left(v_{L}, v_{G}\right)$ and $v_{\text {opt }}^{1 / 2}\left(v_{L}, v_{G}\right) \leq v_{\text {opt }}^{1}\left(v_{L}, v_{G}\right)$, which contradict $\operatorname{AIC}\left(v_{L}, v_{G}\right) \leq \bar{C}$. The result now follows similarly to the previous case. 


\section{PROOF OF OBSERVATION 1:}

We prove that an $\mathbf{S}$-efficient final allocation is implementable as an ex post equilibrium if the reallocation cost functions $C^{G}$ and $C^{L}$ satisfy increasing differences in $\left(v_{L}, \Delta\right)$ and decreasing differences in $\left(v_{G}, \Delta\right) \cdot{ }^{17}$

To do this, we demonstrate that there exists a payment schedule $t_{1}(\cdot, \cdot)$, which is a function of both players' valuations, that supports ex post incentive compatibility for player 1; the treatment of player 2 is analogous.

By part (a) of Lemma 2 in Segal and Whinston (2011), a sufficient condition is that

(i) $x^{\mathrm{S}}\left(v_{1}, v_{2}\right)$ increases in $v_{1}$ for every $v_{2}$, and

(ii) $u\left(v_{1}, v_{2}, x, s\right)$ satisfies increasing differences in $\left(v_{1}, x\right)$ for every $v_{2}$ and $s$.

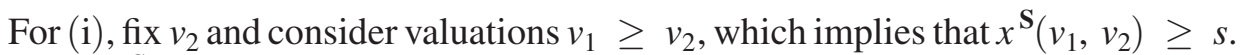
Because $x \mathbf{S}\left(v_{1}, v_{2}\right)$ maximizes the sum of the players' utilities (surplus), we can apply Topkis's (1998) theorem 2.8.7 to show that $x \mathbf{S}\left(v_{1}, v_{2}\right)$ increases in $v_{1}$. For this it suffices to show that

$$
\begin{aligned}
f\left(v_{1}, x\right) & \equiv u_{1}\left(v_{1}, v_{2}, x, s\right)+u_{2}\left(v_{1}, v_{2}, 1-x, 1-s\right) \\
& =x v_{1}-C^{G}\left(v_{2}, v_{1}, x-s\right)+(1-x) v_{2}-C^{L}\left(v_{2}, v_{1}, x-s\right) \\
& =v_{1} x+(1-x) v_{2}-C\left(v_{2}, v_{1}, x-s\right)
\end{aligned}
$$

satisfies strict increasing differences in $\left(v_{1}, x\right)$ when $v_{1} \geq v_{2}$ and $x$ is in $[s, 1] .18$ Since $v_{1}=v_{G}$ and $C^{G}$ and $C^{L}$ satisfy decreasing differences in $\left(v_{G}, x-s\right)$, we have that $-C=-C^{G}-C^{L}$ satisfies increasing differences in $\left(v_{1}, x\right)$. In addition, $v_{1} x$ satisfies strict increasing differences in $\left(v_{1}, x\right)$ and $(1-x) v_{2}$ satisfies increasing differences in $\left(v_{1}, x\right)$. Therefore, $f$ satisfies strict increasing differences in $\left(v_{1}, x\right)$, so $x \mathbf{S}\left(v_{1}, v_{2}\right)$ increases in $v_{1}$. A similar argument shows that $x \mathbf{S}\left(v_{1}, v_{2}\right)$ increases in $v_{1}$ for $v_{1} \leq v_{2}$. Finally, because for $v_{1}$ and $v_{1}^{\prime}$ such that $v_{1}^{\prime} \geq v_{2} \geq v_{1}$ we have $x \mathbf{S}\left(v_{1}^{\prime}, v_{2}\right) \geq s \geq x \mathbf{S}\left(v_{1}, v_{2}\right)$, we conclude that $x \mathbf{S}\left(v_{1}, v_{2}\right)$ increases in $v_{1}$.

For (ii), suppose that $x$ is in $[s, 1]$, and hence $u\left(v_{1}, v_{2}, x, s\right)=x v_{1}-$ $C^{G}\left(v_{2}, v_{1}, x-s\right)$. Since $x v_{1}$ satisfies increasing differences in $\left(v_{1}, x\right)$ and $C^{G}$ satisfies decreasing differences in $\left(v_{1}, x-s\right)$, we are done. A similar argument applies to $x$ in $[0, s]$. Finally, consider $x^{\prime}$ and $x$ such that $x^{\prime} \geq s \geq x$. We have that

$$
\begin{aligned}
& u\left(v_{1}, v_{2}, x^{\prime}, s\right)-u\left(v_{1}, v_{2}, x, s\right) \\
& \quad=x^{\prime} v_{1}-C^{G}\left(v_{2}, v_{1}, x^{\prime}-s\right)-\left(x v_{1}-C^{L}\left(v_{1}, v_{2}, s-x\right)\right) \\
& \quad=\left(x^{\prime}-x\right) v_{1}-C^{G}\left(v_{2}, v_{1}, x^{\prime}-s\right)+C^{L}\left(v_{1}, v_{2}, s-x\right) .
\end{aligned}
$$

\footnotetext{
${ }^{17}$ Let $\mathcal{V}$ and $\mathcal{X}$ be two sets of real numbers. A function $f: \mathcal{V} \times \mathcal{X} \rightarrow \mathbb{R}$ satisfies (strict) increasing differences in $(v, x)$ if $g(v)=f\left(v, x^{\prime}\right)-f(v, x)$ (strictly) increases in $v$ for any $x^{\prime}>x$. If $g(v)$ (strictly) decreases in $v$, then $f$ satisfies (strict) decreasing differences in $(v, x)$.

${ }^{18}$ This would satisfy the conditions of Topkis's theorem because $f$ is trivially quasisupermodular in $x$, and strict increasing differences in $\left(v_{1}, x\right)$ implies the strict single crossing property in $\left(v_{1}, x\right)$.
} 
To show that the expression increases in $v_{1}$, it suffices to show that $C^{G}\left(v_{2}, v_{1}, x^{\prime}-s\right)$ decreases in $v_{1}$ and $C^{L}\left(v_{2}, v_{1}, s-x\right)$ increases in $v_{1}$. Because $C^{G}$ satisfies decreasing differences in $\left(v_{G}, \Delta\right)$, for $v_{1}^{\prime}>v_{1}$ we have that $C^{G}\left(v_{2}, v_{1}^{\prime}, x^{\prime}-s\right)-C^{G}\left(v_{2}, v_{1}^{\prime}, 0\right) \leq C^{G}\left(v_{2}, v_{1}, x^{\prime}-s\right)-C^{G}\left(v_{2}, v_{1}, 0\right)$; and because $C^{G}(\cdot, \cdot, 0)=0$, we have that $C^{G}\left(v_{2}, v_{1}^{\prime}, x^{\prime}-s\right) \leq C^{G}\left(v_{2}, v_{1}, x^{\prime}-s\right)$. Similarly, $C^{L}\left(v_{2}, v_{1}^{\prime}, s-x\right) \geq C^{L}\left(v_{2}, v_{1}, s-x\right)$.

\section{PROOF OF PROPOSITION 5:}

The proof uses the notation and (4) in the proof of Proposition 6 below.

By the envelope theorem (Milgrom and Segal 2002, Section 3.1), player 1's utility in any mechanism that implements an $\mathbf{S}$-efficient final allocation $x^{\mathbf{S}}$ when his type is $v_{1}$ is equal to $U\left(s, v_{1}\right)+K$, where

$$
U\left(s, v_{1}\right)=\int_{0}^{v_{1}} E_{v_{2}}\left(x \mathbf{S}\left(v, v_{2}\right)\right) d v
$$

and $K$ is some constant. By comparing $U\left(s, v_{1}\right)$ to a VCG mechanism that generates the same interim utilities for player 1 and noting that $U(s, 0)=0$, we have that $U\left(s, v_{1}\right)=E_{v_{2}}\left(A^{\mathbf{S}}\left(v_{1}, v_{2}\right)\right)-E_{v_{2}}\left(A^{\mathbf{S}}\left(0, v_{2}\right)\right)$, so

$$
H(s)=U\left(s, v^{*}(s)\right)+E_{v_{2}}\left(A^{\mathbf{S}}\left(0, v_{2}\right)\right)-s v^{*}(s) .
$$

Consider costs $C(x)=b x$ with $b \geq 0$. By Propositions 2 and $3, A(s)$ is constant in $s$. For $b \geq 1 / 2$ the costs are substantial, so by Proposition 6 the second-period deficit is constant in the initial concentration. To show that for $b<1 / 2$ the second-period deficit strictly increases, in the initial concentration, it suffices by (4) to show that $H(s)$ is strictly concave in $s$ for $s \in(0,1)$, since then $H(s)+H(1-s)$ strictly decreases in $s \in(1 / 2,1)$.

Differentiating with respect to $v_{1},(1)$ and the definition of $x^{\mathbf{S}}$ imply that

$$
\begin{aligned}
U_{2}\left(s, v_{1}\right) & =F\left(v_{1}-b\right)+s\left(F\left(v_{1}+b\right)-F\left(v_{1}-b\right)\right) \\
& =(1-s) F\left(v_{1}-b\right)+s F\left(v_{1}+b\right) .
\end{aligned}
$$

In addition, because $U\left(s, v_{1}\right)-s v_{1}$ is minimized at $v_{1}=v^{*}(s)$, setting $v_{1}=v^{*}(s)$ in (3) we obtain

$$
\begin{aligned}
& (1-s) F\left(v^{*}(s)-b\right)+s F\left(v^{*}(s)+b\right) \\
& \quad=s \Rightarrow(1-s) F\left(v^{*}(s)-b\right)=s\left(1-F\left(v^{*}(s)+b\right)\right) \cdot 19
\end{aligned}
$$

\footnotetext{
${ }^{19}$ If $v^{*}(s)$ is interior, then $U_{2}\left(s, v^{*}(s)\right)=s$ because $U(s, v)-s v$ is minimized at $v^{*}(s)$. And $U_{2}(0, v)=E_{v_{2}}\left(x^{s}\left(0, v_{2}\right)\right) \leq s$, but $0 \in \arg _{\max _{v_{1}}}\left\{s v_{1}-U\left(s, v_{1}\right)\right\}$ implies $s \leq U_{2}(0, v)$; similarly, $U_{2}(1, v)=E_{v_{2}}\left(x^{s}\left(1, v_{2}\right)\right) \geq s$, but $1 \in \arg \max _{v_{1}}\left\{s v_{1}-U\left(s, v_{1}\right)\right\}$ implies $s \geq U_{2}(1, v)$.
} 
This equality implies that $v^{*}(s) \in(b, 1-b)$ (since $s \in(0,1)$ and $\left.b<1 / 2\right)$, so $v^{*}(s)-b, F\left(v^{*}(s)-b\right)>0$ and $v^{*}(s)+b, F\left(v^{*}(s)+b\right)<1$. From (2) we have that

$$
\begin{aligned}
H^{\prime \prime}(s) & =\frac{\partial^{2}\left(U\left(s, v^{*}(s)\right)+E_{v_{2}}\left(A^{\mathbf{S}}\left(0, v_{2}\right)\right)-s v^{*}(s)\right)}{\partial s^{2}} \\
& =\frac{\partial^{2}\left(U\left(s, v^{*}(s)\right)-s v^{*}(s)\right)}{\partial s^{2}},
\end{aligned}
$$

where the second inequality follows from $\partial^{2} E_{v_{2}}\left(A\left(0, v_{2}\right)\right) / \partial s^{2}=0$, which follows from

$$
E_{v_{2}}\left(A^{\mathrm{S}}\left(0, v_{2}\right)\right)=(1-s) E_{v_{2}}\left(v_{2}\right)+s \int_{b}^{1}\left(v_{2}-b\right) f\left(v_{2}\right) d v_{2} .
$$

Letting $K(s)=U\left(s, v^{*}(s)\right)-s v^{*}(s)$, we have that

$$
\begin{aligned}
K^{\prime}(s) & =U_{1}\left(s, v^{*}(s)\right)+U_{2}\left(s, v^{*}(s)\right)\left(v^{*}(s)\right)^{\prime}-v^{*}(s)-s\left(v^{*}(s)\right)^{\prime} \\
& =U_{1}\left(s, v^{*}(s)\right)-v^{*}(s)
\end{aligned}
$$

where the last inequality follows from $U_{2}\left(s, v^{*}(s)\right)=s$. We therefore have

$$
\begin{aligned}
K^{\prime \prime}(s) & =U_{11}\left(s, v^{*}(s)\right)+U_{12}\left(s, v^{*}(s)\right)\left(v^{*}(s)\right)^{\prime}-\left(v^{*}(s)\right)^{\prime} \\
& =U_{11}\left(s, v^{*}(s)\right)+\left(U_{12}\left(s, v^{*}(s)\right)-1\right)\left(v^{*}(s)\right)^{\prime} .
\end{aligned}
$$

We have that $U_{11}\left(s, v^{*}(s)\right)=0$, because by (3)

$$
U\left(s, v_{1}\right)=\left(\int_{0}^{v_{1}}((1-s) F(v-b)+s F(v+b)) d v\right) .
$$

In addition, $U_{2}\left(s, v^{*}(s)\right)=(1-s) F\left(v_{1}^{*}-b\right)+s F\left(v_{1}^{*}+b\right)$, so

$$
U_{12}\left(s, v^{*}(s)\right)=U_{21}\left(s, v^{*}(s)\right)=F\left(v_{1}^{*}+b\right)-F\left(v_{1}^{*}-b\right) \in(0,1) .
$$


By the implicit function theorem for $g\left(s, v^{*}(s)\right)=(1-s) F\left(v^{*}(s)-b\right)-$ $s\left(1-F\left(v^{*}(s)+b\right)\right)=0$, we have that

$$
\left(v^{*}(s)\right)^{\prime}=-\frac{g_{1}\left(s, v^{*}(s)\right)}{g_{2}\left(s, v^{*}(s)\right)}=\frac{F\left(v^{*}(s)-b\right)+\left(1-F\left(v^{*}(s)+b\right)\right)}{(1-s) f\left(v^{*}(s)-b\right)+s f\left(v^{*}(s)+b\right)},
$$

so

$$
\begin{aligned}
H^{\prime \prime}(s)=K^{\prime \prime}(s)= & \left(F\left(v^{*}(s)+b\right)-F\left(v^{*}(s)-b\right)-1\right) \\
& \times \frac{F\left(v^{*}(s)-b\right)+\left(1-F\left(v^{*}(s)+b\right)\right)}{(1-s) f\left(v^{*}(s)-b\right)+s f\left(v^{*}(s)+b\right)} \\
= & -\frac{\left(F\left(v^{*}(s)+b\right)-F\left(v^{*}(s)-b\right)-1\right)^{2}}{(1-s) f\left(v^{*}(s)-b\right)+s f\left(v^{*}(s)+b\right)}<0,
\end{aligned}
$$

where the inequality follows from $F\left(v^{*}(s)-b\right)>0$ and $F\left(v^{*}(s)+b\right)<1$. Thus, $H(\cdot)$ is strictly concave.

\section{PROOF OF PROPOSITION 6:}

Choose an initial division $\mathbf{S}$. We begin by deriving an expression for the second-period deficit. For this we observe that for any mechanism that implements an S-efficient final allocation there is a VCG mechanism that generates the same interim utilities to the players and the same (expected) deficit. Therefore, the second-period deficit is equal to the deficit that arises in an individually rational VCG mechanism in which the players obtain the lowest possible utilities. We therefore compute the deficit in such a VCG mechanism. ${ }^{20}$

To do this, suppose without loss of generality that player 1's initial share is $s=s_{\text {max }}$, and recall that in a VCG mechanism, player 1 's utility is $A^{\mathbf{S}}\left(v_{1}, v_{2}\right)-$ $h^{\mathbf{S}}\left(v_{2}\right)$, where $A^{\mathbf{S}}$ is the ex post surplus in an $\mathbf{S}$-efficient final allocation $x \mathbf{S}$ and $h^{\mathbf{S}}$ is some function of $v_{2}$.

Let $H(s)=\min _{v_{1}}\left\{E_{v_{2}}\left(A^{\mathbf{S}}\left(v_{1}, v_{2}\right)\right)-s v_{1}\right\}$ be the highest value of $E\left(h^{\mathbf{S}}\left(v_{2}\right)\right)$ such that all of player 1's participation constraints hold, and denote by $v^{*}(s) \in \arg \min _{v_{1}}\left\{E_{v_{2}}\left(A^{\mathbf{S}}\left(v_{1}, v_{2}\right)\right)-s v_{1}\right\}$ a "binding valuation." Thus, the minimal expected utility that player 1 can get while satisfying his participation constraints is $A(s)-H(s)$, where $A(s)=E\left(A^{\mathbf{S}}\left(v_{1}, v_{2}\right)\right)$ is the maximal expected surplus. Since $A(s)-H(1-s)$ is the corresponding utility for player 2 , and the available expected surplus, generated by $x^{\mathrm{S}}$, is $A(s)$, we obtain that the deficit is

\footnotetext{
${ }^{20}$ This approach was formalized by Williams (1999) and then shown to hold under more general conditions by Segal and Whinston's (2012) lemma 3 part (ii), whose conditions are satisfied here. Our derivation is similar to their derivation of equation (15).
} 
(4)

$$
A(s)-H(s)+A(s)-H(1-s)-A(s)=A(s)-H(s)-H(1-s) .
$$

Also, by definition

$$
H(s)=\underbrace{E_{v_{2}}\left(A^{\mathrm{S}}\left(v^{*}(s), v_{2}\right)-s v^{*}(s)-(1-s) v_{2}\right)}_{\text {Expected gains from reallocation }}+(1-s) E\left(v_{2}\right),
$$

so $H(s)+H(1-s)$ is no lower than each player's expected valuation for the asset, and the two are equal if and only if for each player it is optimal for no reallocation to take place with probability 1 when he has a binding valuation. Moreover, if a player has a valuation for which no reallocation is optimal, then this valuation minimizes the expected gains from reallocation, and therefore, by definition of $v^{*}$, it is binding. Thus, when reallocation costs are substantial, the deficit is as stated in the proposition.

\section{PROOF OF PROPOSITION 7:}

Suppose first that costs are amount-insensitive or concave. This implies that if some of the asset is optimally reallocated from player $i$ to player $j$, then player $i$ 's entire initial share is optimally reallocated to player $j$. Thus, an $\mathbf{S}$-efficient final allocation is characterized, for any realization of players' valuations, by a partition of the set of players and a player within each element of the partition, such that for each element of the partition the shares of all the players in the element are reallocated to the specified player in the element (singleton elements corresponds to maintaining the initial shares). Thus, the maximal expected surplus is

$A(\mathbf{S})$

$$
=E\left(\max _{\left\{\mathcal{I}_{1}, i_{1} \ldots, \mathcal{I}_{K}, i_{K}: K \geq 1, i_{k} \in \mathcal{I}_{k}, \text { and } \bigsqcup_{k \leq K} \mathcal{I}_{k}=N\right\}}\left\{\sum_{k=1}^{K}\left(v_{i_{k}}\left(\sum_{j \in \mathcal{I}_{k}} s_{j}\right)-\sum_{j \in \mathcal{I}_{k} \backslash\left\{k_{k}\right\}} C\left(v_{j}, v_{i_{k}}, s_{j}\right)\right)\right\}\right) .
$$

Because each of the functions over which the maximum is taken is convex in $\mathbf{S}$, the maximum of convex functions is a convex function, and the integral of convex functions is a convex function, we have that $A$ is a convex function of $\mathbf{S}$. In addition, $A$ is symmetric (i.e., its value does not change under permutations of $\mathbf{S}$ ) because $F$ is symmetric. A convex symmetric function is Schur-convex (Schur 1923), i.e., $A(\mathbf{S}) \geq A(\mathbf{T})$ if $\mathbf{S}$ majorizes $\mathbf{T}$.

Now suppose that costs are convex. Given a realization of players' valuations, an S-efficient final allocation optimally reallocates each player's initial share between this player and players with higher valuations. To formalize this, denote by $\Pi$ the set of permutations of $1, \ldots, N$, so that $\pi(i)$ is the element in the $i$ th position in the permutation $\pi \in \Pi$. Ignoring, for notational simplicity, the expected value of the 
asset and realizations in which not all valuations are distinct, the maximal expected surplus is

$$
\begin{aligned}
& A(\mathbf{S}) \\
& =\sum_{\pi \in \Pi} \int_{v_{\pi(1)}>\cdots>v_{\pi(N)}}\left(\sum_{i=2}^{N}\left\{\max _{x_{1}^{i}, \ldots, x_{i-1}^{i} \geq 0: \sum_{j=1}^{i-1} x_{j}^{i} \leq s_{\pi(i)}} \sum^{i-1}\left(\left(v_{\pi(j)}-v_{\pi(i)}\right) x_{j}^{i}-C\left(v_{\pi(i)}, v_{\pi(j)}, x_{j}^{i}\right)\right)\right) d F .\right.
\end{aligned}
$$

Because sums and integrals of concave functions are concave, to prove that $A(\mathbf{S})$ is concave it suffices to show that for any permutation $\pi$ and realization $v_{\pi(1)}>\cdots>v_{\pi(N)}$ of players' valuations

$$
\left.h(\mathbf{S})=\max _{\left\{x_{1}^{i}, \ldots, x_{i-1}^{i} \geq 0: \sum_{j=1}^{i-1} x_{j}^{i} \leq s_{\pi(i)}\right.}\right\} \sum_{j=1}^{i-1}\left(\left(v_{\pi(j)}-v_{\pi(i)}\right) x_{j}^{i}-C\left(v_{\pi(i)}, v_{\pi(j)}, x_{j}^{i}\right)\right)
$$

is concave in $\mathbf{S}$. Consider initial divisions $\mathbf{S}$ and $\mathbf{S}^{\prime}$ and corresponding maximizing vectors $\mathbf{x}(\mathbf{S})$ and $\mathbf{x}\left(\mathbf{S}^{\prime}\right)$. Let $\mathbf{T}=\alpha \mathbf{S}+(1-\alpha) \mathbf{S}^{\prime}$ and $y=\alpha \mathbf{x}(\mathbf{S})+$ $(1-\alpha) \mathbf{x}\left(\mathbf{S}^{\prime}\right)$ for some $\alpha \in[0,1]$. We then have

$$
\begin{aligned}
h(\mathbf{T}) \geq & \sum_{j=1}^{i-1}\left(\left(v_{\pi(j)}-v_{\pi(i)}\right) y_{j}^{i}-C\left(v_{\pi(i)}, v_{\pi(j)}, y_{j}^{i}\right)\right) \\
= & \alpha \sum_{j=1}^{i-1}\left(v_{\pi(j)}-v_{\pi(i)}\right) x(\mathbf{S})_{j}^{i}+(1-\alpha) \sum_{j=1}^{i-1}\left(v_{\pi(j)}-v_{\pi(i)}\right) x\left(\mathbf{S}^{\prime}\right)_{j}^{i} \\
& -\sum_{j=1}^{i-1} C\left(v_{\pi(i)}, v_{\pi(j)}, \alpha x(\mathbf{S})_{j}^{i}+(1-\alpha) x\left(\mathbf{S}^{\prime}\right)_{j}^{i}\right) \\
\geq & \alpha h(\mathbf{S})+(1-\alpha) h\left(\mathbf{S}^{\prime}\right) .
\end{aligned}
$$

In addition, $A(\mathbf{S})$ is symmetric because $F$ is symmetric, so by Schur-convexity $-A(\mathbf{S}) \geq-A\left(\mathbf{S}^{\prime}\right)$ if $\mathbf{S}$ majorizes $\mathbf{S}^{\prime}$, i.e., $A\left(\mathbf{S}^{\prime}\right) \geq A(\mathbf{S})$.

\section{REFERENCES}

Arrow, Kenneth. 1979. "The Property Rights Doctrine and Demand Revelation under Incomplete Information." In Economics and Human Welfare, edited by M. Boskin, 23-39. New York: Academic Press.

- Cadenillas, Abel. 2000. "Consumption-investment problems with transaction costs: Survey and open problems." Mathematical Methods of Operations Research 51 (1): 43-68.

-Cramton, Peter, Robert Gibbons, and Paul Klemperer. 1987. "Dissolving a Partnership Efficiently." Econometrica 55 (3): 615-32.

-Crémer, Jacques, and Richard P. McLean. 1988. "Full Extraction of the Surplus in Bayesian and Dominant Strategy Auctions." Econometrica 56 (6): 1247-57.

$\checkmark$ d'Aspremont, Claude, and Louis-André Gérard-Varet. 1979. "Incentives and incomplete information." Journal of Public Economics 11 (1): 25-45. 
Dybvig, Philip H. 2005. "Mean-Variance Portfolio Rebalancing with Transaction Costs." http:// phildybvig.com/papers/tcost1per2.pdf.

-Fieseler, Karsten, Thomas Kittsteiner, and Benny Moldovanu. 2003. "Partnerships, lemons, and efficient trade." Journal of Economic Theory 113 (2): 223-34.

- Grossman, Sanford J., and Oliver D. Hart. 1986. "The Costs and Benefits of Ownership: A Theory of Vertical and Lateral Integration." Journal of Political Economy 94 (4): 691-719.

-Hart, Oliver, and John Moore. 1990. "Property Rights and the Nature of the Firm." Journal of Political Economy 98 (6): 1119-58.

- Jehiel, Philippe, and Ady Pauzner. 2006. "Partnership dissolution with interdependent values." RAND Journal of Economics 37 (1): 1-22.

-Kosenok, Grigory, and Sergei Severinov. 2008. "Individually rational, budget-balanced mechanisms and allocation of surplus." Journal of Economic Theory 140 (1): 126-61.

-Kószegi, Botond, and Matthew Rabin. 2006. "A Model of Reference-Dependent Preferences." Quarterly Journal of Economics 121 (4): 1133-65.

Mas-Colell, Andreu, Michael D. Whinston, and Jerry R. Green. 1995. Microeconomic Theory. Oxford: Oxford University Press.

-McAfee, R. Preston, and Philip J. Reny. 1992. "Correlated Information and Mechanism Design." Econometrica 60 (2): 395-421.

-Milgrom, Paul, and Ilya Segal. 2002. "Envelope Theorems for Arbitrary Choice Sets." Econometrica 70 (2): 583-601.

Mitchell, John E., and Stephen Braun. 2004. "Rebalancing an Investment Portfolio in the Presence of Convex Transaction Costs." http://www.optimization-online.org/DB_FILE/2005/01/1050.pdf.

-Myerson, Roger B., and Mark A. Satterthwaite. 1983. "Efficient mechanisms for bilateral trading." Journal of Economic Theory 29 (2): 265-81.

Schur, Issai. 1923. "Uber eine Klasse von Mittelbildungen mit Anwendungen die Determinanten." Theorie Sitzungsber 22: 9-20.

-Segal, Ilya R., and Michael D. Whinston. 2011. "A simple status quo that ensures participation (with application to efficient bargaining)." Theoretical Economics 6 (1): 109-25.

Segal, Ilya, and Michael D. Whinston. 2012. "Property Rights." In Handbook of Organizational Economics, edited by R. Gibbons and J. Roberts, 100-158. Princeton: Princeton University Press.

Topkis, Donald M. 1998. Supermodularity and Complementarity. Princeton: Princeton University Press.

- Tversky, Amos, and Daniel Kahneman. 1991. "Loss Aversion in Riskless Choice: A Reference-Dependent Model." Quarterly Journal of Economics 106 (4): 1039-61.

-Williams, Steven R. 1999. "A characterization of efficient Bayesian incentive compatible mechanisms." Economic Theory 14 (1): 155-80. 